\title{
CULTURE AS A WEAPON IN THE CONTEXT OF CURRENT AND FUTURE OPERATIONAL ENVIRONMENTS
}

\author{
Paul TUDORACHE, Lucian ISPAS \\ "Nicolae Bălcescu” Land Forces Academy, Sibiu, Romania \\ p_tudorache@yahoo.com, ispaslucian04@yahoo.com
}

\begin{abstract}
The study of the cultural factor's influence on military actions is not a recent issue, the main concerns being aimed at identifying some solutions for the improvement of the cooperation between different national contingents during stability and support operations. Instead, the use of culture as a weapon in the sense of military capability used to predict and influence the behavior of target groups is a completely new approach, currently being within reach of only few modern armies. From another perspective, the possibility of using engagement as a new war fighting function, assuming the development of skills and capabilities necessary to deal with the local population and regional security forces, determines the necessity to educate and develop a cultural capability for all military personnel. This can be identified as a real solution for the military forces in improving their missions' accomplishment within the context of current and future operational environments.
\end{abstract}

\section{Keywords: cultural capability, cultural operationalization, engagement, operational environment}

\section{Introduction}

The context of military engagement in the conduct of various missions across the whole spectrum of operations (Full Operations Spectrum - FOS) is in a pronounced dynamics, generally determined by the permanent adaptation of hypothetical opponents to the development trends of military capabilities, as well as to their permanent operational evolution, involving the improvement of tactics, techniques and procedures (Tactics, Techniques, and Procedures) used. Moreover, as far as the opponent's operational behavior is concerned, it can be described as a very unpredictable one, correlating the use of conventional military forces with unconventional forces, which include insurgents, guerrilla, organized crime, militarized criminal gangs, etc.

Also, with regard to the role of the other actors present in the operational environment, there is a growing tendency for the local population, regional (local) security forces, non-governmental organizations (NGOs), agencies, international organizations and non-governmental organizations to get increasingly involved. Having these established coordinates, to which can be added the increase in the share of the use of asymmetric actions by the opponent, we can conclude that the current operational environment, especially the one that is to be seen in the future, will be volatile, uncertain, complex and ambiguous (Volatile, Uncertain, Complex and Ambiguous - VUCA).

Accepting the principle according to which the role of non-lethal capabilities has increased significantly, the armies in general and the United States of America (USA) in particular are making sustained efforts to form and develop new capabilities, such as the cultural one, necessary to support the 
forces in accomplishing the entire spectrum of missions in any type of operational environment, regardless of its difficulty. The use of such a capability, which simplistically allows for "the use of culture as a weapon", has multiple implications in the conduct of military operations, starting with the coalition partners, continuing with the other actors in the operational environment, especially the local population and local/regional security forces, and finishing with the opponent.

\section{Engagement - a new warfighting function for future land operations?}

Lately, taking into account the more pronounced role of the other actors of the operational environment in the conduct of military actions, at the level of modern armies, steps have been taken to analyze and update the war fighting functions in order to respond to the demands of the current and future operational environments. Generally, at the level of most armies within NATO, war fighting functions are as follows: command, informational activities, intelligence, maneuver, fire support, protection, and logistical support (sustainment) [1]. Another classification that is circulated within NATO refers to: "maneuver, fire support, intelligence, protection (mobility, counter-mobility and survivability), air defense, combat service support and command and control" [2].

Analyzing both classifications, it can easily be noticed that only the informational activities are most closely related to the relationship with the other actors of the operational environment, by pursuing through specific information operations, such as psychological operations (PSYOPS) only the provision of information used to influence their perceptions and understanding. Also, this function of war fighting, manifested through the civilmilitary cooperation (CIMIC), aims at only the relationship with the local population and local governmental officials, which in our view is not sufficient, because other equally important actors operate in the operational environment. Perhaps the most significant aspect, which generates disagreements, is given by the purpose of information operations, consisting in influencing the perception and behavior of individuals in the short term and in no way aiming to develop the medium- and longterm relationships, which have been lacking in recent confrontations.

That is why, from the US Army's point of view, the use of a new war fighting function, such as that of engagement, meets the need for operational adaptation of the military forces, covering the medium- and long-term spectrum of the relationship with all actors present in the operational environment. As a consequence, the US Army's vision of combat functions is the one presented in Table 1, the last one, namely engagement being under implementation.

Table no. 1. War fighting functions according with US Army doctrine [3]

\begin{tabular}{|l|l|c|}
\hline $\begin{array}{c}\text { War fighting } \\
\text { functions }\end{array}$ & \multicolumn{1}{|c|}{ Significance } & Status \\
\hline $\begin{array}{l}\text { Mission } \\
\text { command }\end{array}$ & $\begin{array}{l}\text { develop and integrate those activities enabling a commander } \\
\text { to balance the art of command and the science of control in } \\
\text { order to integrate the other war fighting functions }\end{array}$ & approved \\
\cline { 1 - 2 } $\begin{array}{l}\text { Movement } \\
\text { and maneuver }\end{array}$ & $\begin{array}{l}\text { move and employ forces to achieve a position of relative } \\
\text { advantage over the enemy and other threats }\end{array}$ & $\begin{array}{l}\text { facilitate understanding the enemy, terrain, weather, civil } \\
\text { considerations, and other significant aspects of the operational } \\
\text { environment }\end{array}$ \\
\hline Intelligence & $\begin{array}{l}\text { provide collective and coordinated use of Army indirect fires, air } \\
\text { and missile defense, and joint fires through the targeting process }\end{array}$ & \\
\hline
\end{tabular}




\begin{tabular}{|c|c|c|}
\hline $\begin{array}{l}\text { War fighting } \\
\text { functions }\end{array}$ & Significance & Status \\
\hline Sustainment & $\begin{array}{l}\text { provide support and services to ensure freedom of action, } \\
\text { extend operational reach, and prolong endurance }\end{array}$ & \\
\hline Protection & $\begin{array}{l}\text { preserve the force so the commander can apply maximum } \\
\text { combat power to accomplish the mission }\end{array}$ & \\
\hline Engagement & $\begin{array}{l}\text { provide skills and capabilities necessary to interact with host } \\
\text { nations, regional partners and indigenous populations [4] }\end{array}$ & $\begin{array}{l}\text { pending } \\
\text { approval }\end{array}$ \\
\hline
\end{tabular}

From a broader perspective, again relating to the US Army doctrine, engagement aims at forming and developing "capabilities and skills necessary to work with host nations, regional partners, and indigenous populations in a culturally attuned manner that allows bridging language barriers, opening lines of communication and connections with key political and military leaders in a way that is both immediate and lasting "[5]. Also, perhaps the most important effect that the application of engagement as a war fighting function can generate lies in the possibility of operationalization of culture at the level of military operations, which briefly refers to the integration of socio-cultural (dynamic) aspects into all the activities of the operations process, and here we are not referring to just planning and execution, as is customary, but also to preparation and evaluation respectively.

\section{Operationalization of culture into military operations}

In general, from the perspective of the cultural factor, the conduct of the multinational military operations requires the participating personnel to demonstrate the knowledge of the host nation's language and culture. This is a very important aspect, but unfortunately not enough. Resorting to the concept of cultural capability whose components are presented in figure no. 1, we note that the previous requirement only covers the first two components, representing the specific culture of the displacement area, which focuses on the relationship with the local population at most.

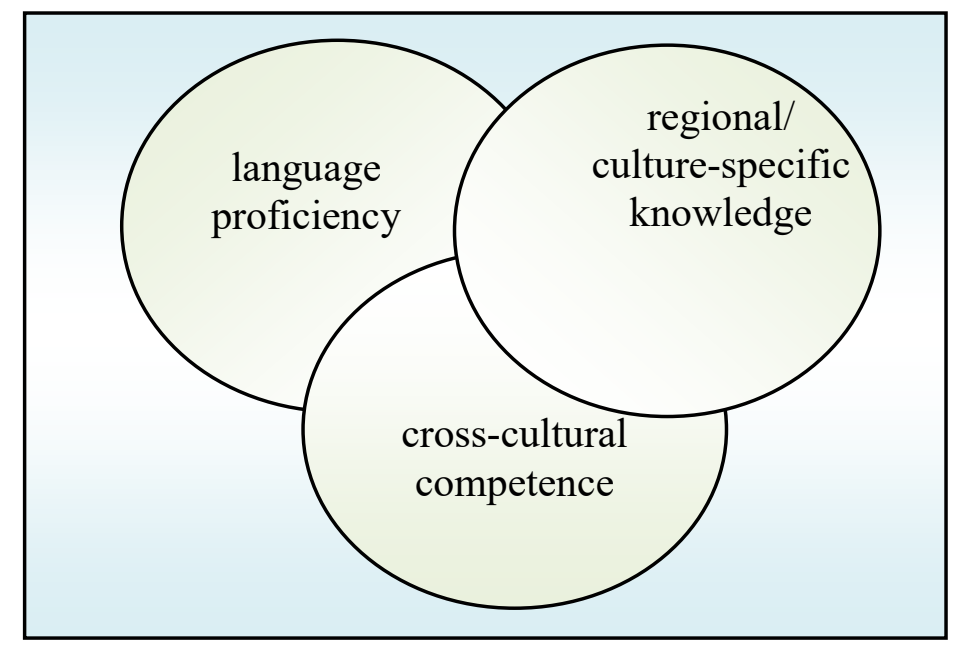

Figure no 1. Components of cultural capability [6]

Therefore, the efficient use of engagement as a function of war fighting involves the development of a cultural capability of the military personnel on all three components, since the last one, the intercultural competence, is also the one that assures the 
application of the socio-cultural aspects in the process of operations, being as a rule required of the specialized staff such as the cultural advisers (CULAD) or foreign area officers $(F A O)$. Only in this way, with the support of CULAD, FAO, Regional Area Officers $(R A O)$, etc. can the coherent integration of the socio-cultural aspects be achieved at the level of military operations. Also, the operationalization of culture at the level of military action implies the understanding of the "relevant aspects of culture that influence military operations and help us understand the effects of our own decisions vis-à-vis the socio-cultural fabric of the operational environment." [7]. It addresses the entire process of operations whose specific activities are planning, preparation, execution and evaluation. Taking as an example the first activity of the operations process, for a multinational tactical level military structure, the operationalization of culture would be confined to the adaptation of the military decision making process $(M D M P)$ by integrating the relevant socio-cultural aspects in all the characteristic steps (Table no. 2). This adaptation modality is absolutely necessary because the MDMP in the proposed formula offers us the possibility to identify the reactions and likely effects of the other actors (at least the local population and regional security forces) on their own courses of action $(C O A)$, on the one hand, and on those of the opponent, on the other hand [8].

Table no. 2. Adapting MDMP using operationalization of culture (adaptation using the model presented in MNE6) [9]

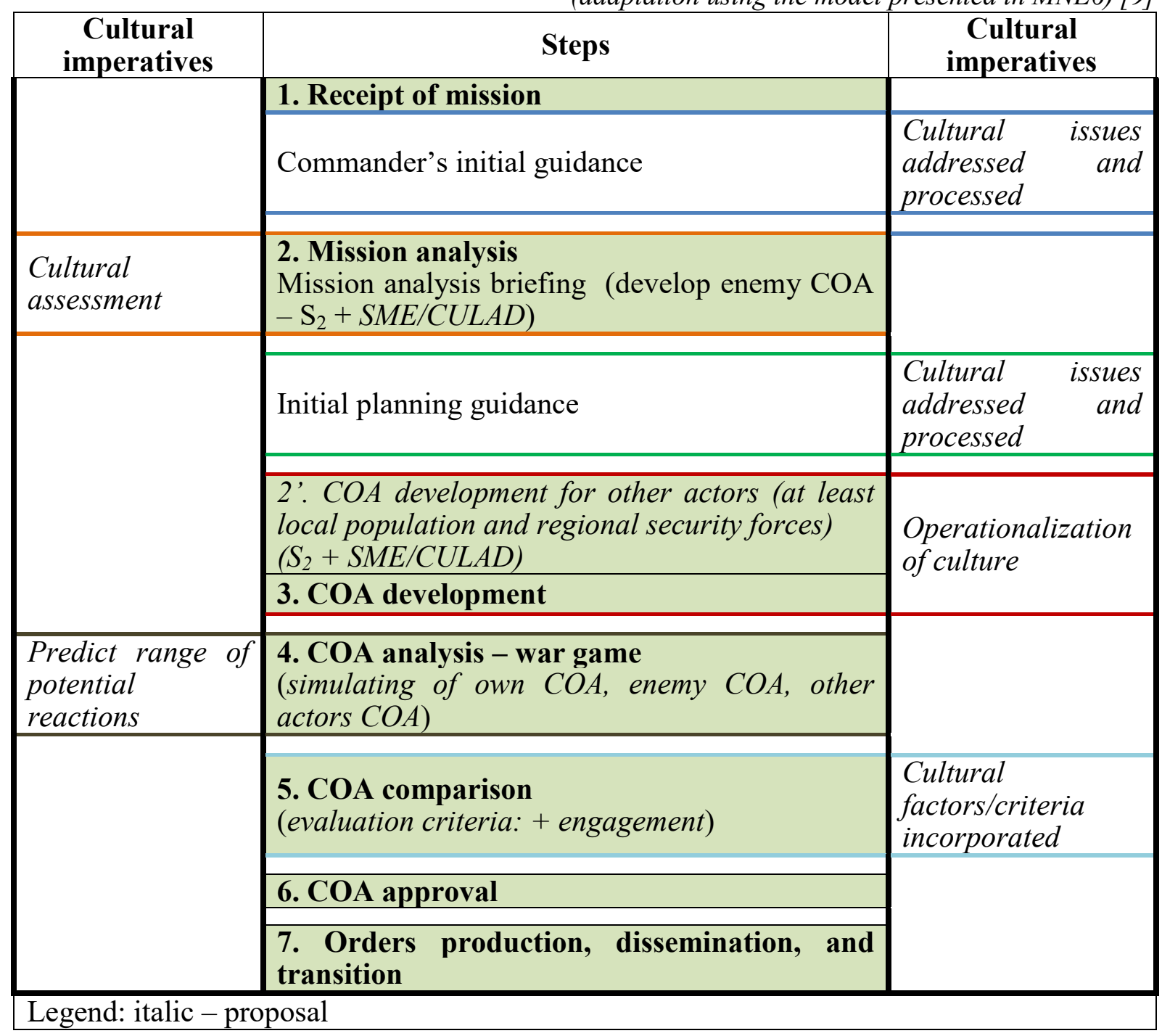


Also, when comparing the COA, in addition to the established benchmarks defined in principle by war fighting functions, engagement should also be mandatorily introduced, thus covering the aspects of the relationship with the local population and the other actors present in the operational environment which may influence the operation of the friendly forces.

During the execution of the operation, the operationalization of the culture focuses very much on the integration of the sociocultural aspects in the battle rhythm, which implies the use of a personnel with a high level of cultural capability, such as CULAD or cultural experts (Subject Metter Expert - SME). Within the activities of the battle rythm, the cultural savvy staff "is to be the actual catalyst that can channel cultural information into decisions that will be further reflected in the working and operational documents produced." [10].

\section{Conclusions}

The emphasis on the role of the other actors, where not few were the situations in which the local population was determined to be a center of gravity $(\mathrm{CoG})$ in the conduct of military operations, obliges us to permanently identify solutions for winning the hearts and minds of this category, and not only, thus enabling the friendly forces to act conventionally against hypothetical opponents, which have recently focused on TTPs, such as camouflaging among it and, as a consequence, masking specific actions.
Also, the VUCA type characteristics specific to the current and future operational environments determine the leadership of military structures to abandon the old habits and identify new ones that they can promote on a permanent basis. In this respect, the use of principles within military operations, such as mission command and maneuverist approach, is a clear demonstration of initiating the operational adaptation of military structures to the new challenges of operational environments. If the former promotes the decision-making initiative of subordinate commanders during execution, the latter proposes an indirect approach of the enemy, primarily aiming at weakening its moral component prior to the decisive lethal engagement.

In this framework, engagement as a war fighting function, implying "the use of culture as a weapon", enables the military forces to amplify the effects of the two principles and even of other war fighting functions, as we have seen through its exercise can lead to the support of the other actors involved, thus reaching an amplified combat power, which appropriately directed can result in the desired final states.

Last but not least, such principles should also be included in the military training and education process, with the clearly defined direction of "preparing leaders to be unprepared" [11]. Only in this way, do we have the hope that leaders and military structures, regardless of their level or nature, will be able to cope with the demands of the current and future operational environments.

\section{References}

[1] AJP-3.2, Allied Joint Doctrine for Land Operations, edition A, version 1, NATO Standardization Office (NSO), March 2016, pp. 2-15.

[2] ATP-3.2.2, Command and Control of Allied Land Forces, edition B, version 1, NATO Standardization Office (NSO), December 2016, p. LEX-4.

[3] ADRP 3-0, Operations, Headquarters, Departement of the Army, Washington DC, October 2017, pp. 5-2 - 5-6.

[4] TRADOC Pam 525-8-5, U.S. Army Functional Concept for Engagement, February 2014, p. iii. 
[5] Ibidem.

[6] Allison Abbe, Study Report 2008-04, Building Cultural Capability for Full-Spectrum Operations, United States Army Research Institute for Behavioral and Social Sciences, January 2008, p. 2.

[7] Ltc Victor Bados, Ltc Jose Martinez-Ferrer, Len lavella, Multinational Experiment 6 (MNE 6), Guidelines for Commanders and Staffs: Operationalization of Culture into Military Operations (Best Practices), November 2010, p. 7.

[8] Ibidem, p. 59.

[9] Ibidem, pp. 22-26.

[10] Ibidem, p. 29.

[11] Paul Tudorache, Lucian Ispas. Educating Land Forces' Leaders to Think from JIIM Perspective, Land Forces Academy Review, No. 4, 2018, p. 255. 